\title{
The Evaluation of Regional Instability to Climate Change Based on the PSA Model-A Case Study of Philippines
}

\author{
Hui Liao, ${ }^{1, ~ *, ~ K u n l i n g ~ H a n ~}{ }^{2}$, Shuo Sun ${ }^{1}$, Yajing Jin ${ }^{1}$ \\ ${ }^{1}$ School of Civil Engineering and Architecture, Shandong University of Science and Technology, Qingdao, China \\ ${ }^{2}$ School of Mathematics and System Science, Shandong University of Science and Technology, Qingdao, China

\section{Email address:} \\ splannerlh@gmail.com (Hui Liao), SDLLHB1218@163.com (Kunling Han),17860755955@163.com (Shuo Sun), \\ jinyajing9320@163.com (Yajing Jin) \\ ${ }^{*}$ Corresponding author
}

\section{To cite this article:}

Hui Liao, Kunling Han, Shuo Sun, Yajing Jin. The Evaluation of Regional Instability to Climate Change Based on the PSA Model—A Case Study of Philippines. American Journal of Civil Engineering. Vol. 6, No. 3, 2018, pp. 99-108. doi: 10.11648/j.ajce.20180603.13

Received: April 24, 2018; Accepted: June 26, 2018; Published: June 27, 2018

\begin{abstract}
In recent years, the ever-changing climate has caused natural disasters in various countries to occur frequently. Climate change has become one of the factors that have caused this country to be vulnerable. This article mainly quantitatively studies how climate change affects regional instability. A comprehensive indicator evaluation method is used to establish a PSA model. The country's vulnerability is defined in terms of the dimensions of pressure, sensitivity, and adaptive capability. This article selected Philippines as the research object, and based on the data processing by PSA model, we obtained the Fragile State Index (FSI) of Philippines in the past ten years. It has found that the flooding in 2012 has made it more vulnerable to Philippines and the results of the analysis are in line with the actual situation. Then, the K-means clustering algorithm is used to get a tipping point (0.5) that can define whether it is fragile or not. What's more, the critical point is verified to be reasonable. Finally, under the guidance of the data of the three dimensions and first-class indicators, the intervention measures that the country should take to address climate change are proposed to reduce regional instability.
\end{abstract}

Keywords: Climate Change, Regional Instability, Fragile State Index, PSA Model

\section{Introduction}

The effects of Climate Change, to include increased droughts, shrinking glaciers, changing animal and plant ranges, and sea level rise, are already being realized and vary from region to region. Many of these effects will alter the way humans live, and may have the potential to cause the weakening and breakdown of social and governmental structures. Consequently, destabilized governments could result in fragile states. Environmental stress alone does not necessarily trigger violent conflict, but evidence suggests that it enables violent conflict when it combines with weak governance and social fragmentation. This confluence can enhance a spiral of violence, typically along latent ethnic and political divisions.

The research on the vulnerability caused by climate change is a major topic at home and abroad. Up to now, there are some studies on vulnerability based on climate change.
Füssel standardized the concept of vulnerability and defined six dimensions of vulnerability assessment [1]. Moss et al. divided the influencing factors of climate change vulnerability at the national level from the three dimensions of natural environment dimension, socioeconomic dimension and external assistance dimension [2]. Klein and Nichols proposed a vulnerability assessment system for both the natural environment and the social economy [3]. Chinese scholars have also conducted valuable research on the factors that influence the vulnerability of climate change. For example, Tan Shuhao et al. assessed the social vulnerability of herdsmen in Inner Mongolia using a comprehensive index assessment method [4]. Xu Tingting et al. used the analytic hierarchy process to focus on the time-series transformation of the social and economic vulnerability in Shanghai under the influence of nature and 
economic and social systems [5]. Feng Chunyan used the principal component analysis method to analyze and classify the social vulnerability of drought in 17 cities in Shandong Province [6]. Qiao Mengmeng used fuzzy matter-element method to assess the vulnerability of Suzhou City's water resources from 2005 to 2015 [7].

Based on the literature analysis above, this article shows that the existing research focuses mainly on the impact of climate change on the instability of provinces or cities in one aspect. However, the comprehensive evaluation and analysis of influencing factors on vulnerability are very lack of. In view of this, based on the results of the existing literature research and combining with the specific conditions of the Philippines, it is proposed to adopt a comprehensive index assessment method to establish a PSA model to measure the impact of climate change on the country; and on this basis, put forward targeted national interventions countermeasures, which aim to increase the adaptability of climate change and reduce the instability in the region.

\section{Research Area and Data}

\subsection{Research Area}

Located in the Western Pacific, the Philippines is a multi-ethnic island nation in Southeast Asia with an area of approximately 299,700 square kilometers and a population of approximately 103 million (2016). The climate of the monsoon-type tropical rainforest in the Philippines is characterized by high temperatures, high rainfall, high humidity, and typhoons. The annual average temperature is about $27^{\circ} \mathrm{C}$, and the average annual precipitation is $2000-3000 \mathrm{~mm}$ in most areas. In the western part of the archipelago, there are dry seasons (November-April next year) and rainy season (May-October). There is lots of rain all year round on the eastern and southern coasts, with the most winter rains. The eastern part of the Pacific Ocean is the birthplace of typhoons, where there are multiple typhoons between June and November each year. The drastic changes in the climate have caused incalculable economic losses in the country. It can thus be seen that the Philippines is a typical region where climate disasters have led to increased national instability.

\subsection{Research Data}

\subsubsection{Data Sources}

Collecting sufficient data is the basis of developing a complete index system. The datas of Afghan are mainly from the website of National Bureau of Statistics (NBS) ${ }^{1}$, World Weather $^{2}$, Sina Finance and Economy ${ }^{3}$ and the World Bank ${ }^{4}$. For the missing indicator data of the website, we obtained

\footnotetext{
$1 \mathrm{http}: / /$ data.stats.gov.cn/easyquery.htm?cn=G0104

$2 \mathrm{https}: / /$ en.tutiempo.net/climate/afghanistan.html

$3 \mathrm{http}: / /$ finance.sina.com.cn/worldmac/index.shtml

$4 \mathrm{https}: / /$ en.tutiempo.net/climate/afghanistan.html
}

data through web crawlers.

\subsubsection{Data Preprocessing}

The availability of data is an essential issue. It is essential to ensure the continuity and authenticity of the research data. Nevertheless, some data is missing because not all data is provided in the website. To ameliorate this situation, some methods are proposed to complete the data, which are as follows:

(1) If the indicator values are smooth, previous data can be adopted to replace it. If the data before and after can be obtained, the average value can be taken as the missing.

(2) If an indicator cannot be found, the passage uses similar indicators to compensate for missing values.

(3) If two groups are similar, then the missing data in one group can be replaced by the value of the same location in the other group.

(4) The interpolation method is used in data fitting.

\section{Research Methods}

\subsection{Assumptions of the Model}

(1) The statistics we collected from the website are reliable and accurate.

(2) Neglect the explosive changes affected by Non-climate change factors when forecasting over the few decades.

(3) "State" refers to a sovereign state or country. A stable regime will be committed to equitable distribution and maintenance of institutions and infrastructure.

\subsection{The Establishment of a Model}

This article has adopted the PSA model, which is the "Pressure-Sensitivity-Adaptive capability" model. From the perspective of system theory, the impact of climate change on the country's vulnerability is a dynamic process that fits this model. This paper will use a comprehensive index assessment method to quantitatively assess the country's vulnerability due to climate change. Based on the definition of vulnerability, we the passage selects 24 representative indicators to construct a national vulnerability evaluation index system. Through the calculation Fragile State Index (FSI) of the research object, this article objectively assesses and analyzes the vulnerability of the Philippines and its causes.

\subsubsection{Selection of Evaluation Indicators}

This article draws on the "Exposure - ensitivity Adaptive capability" analytical framework proposed by the IPCC, and adjusts the parameters on this basis, replacing the "exposure dimension" with the "pressure dimension". The deductive method is used in the process of index selection [8], and full reference is made to the indicators that have contributed to the vulnerability in previous literature. In addition, the National Vulnerability Evaluation Index System has been constructed based on the country's economic, political, cultural, social, and ecological realities. 


\subsubsection{Construction of Evaluation Index System}

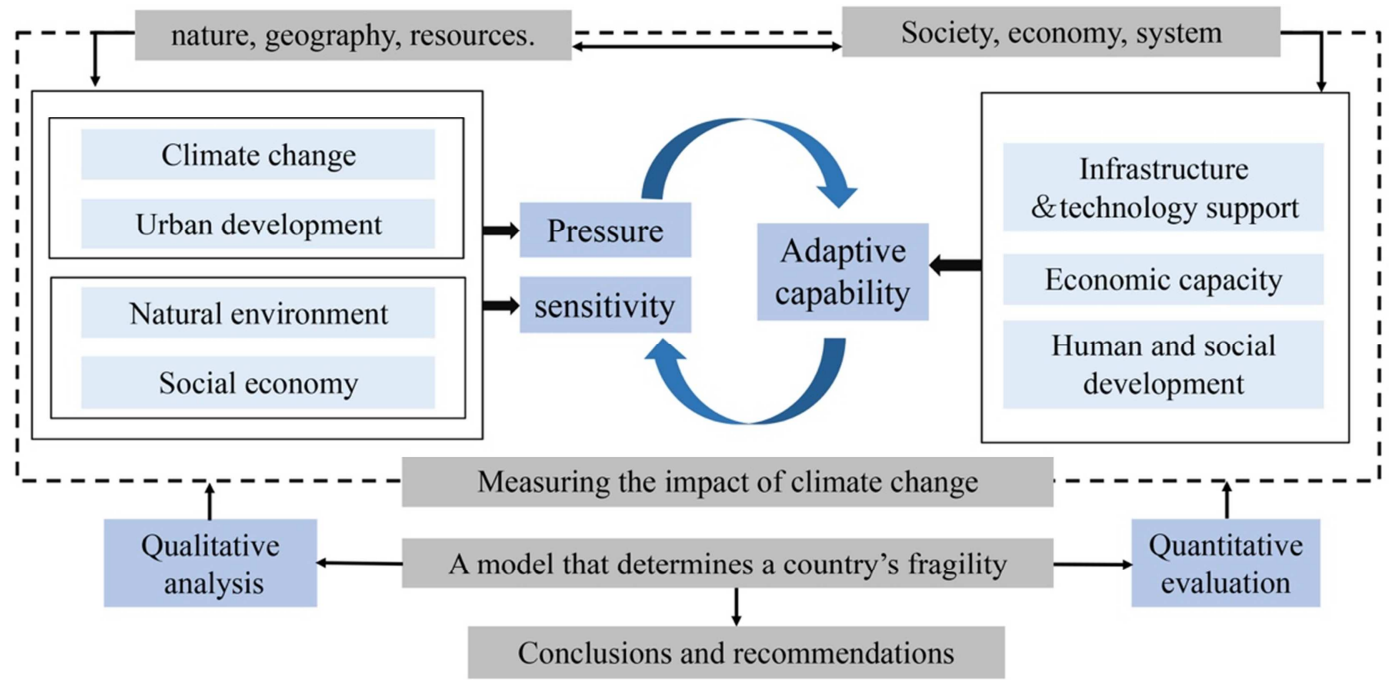

Figure 1. The analysis framework of the model.

(1) Pressure Metric

The metric of pressure not only includes the extent of climate change's impact on the system, but also includes the extent of changes in other associated systems caused by climate change. It is often expressed by the magnitude of the extent of weather change, the frequency, the duration, and the size of the influence range [9]. The higher the pressure metric, the greater the burden of pressure from the natural, economic and social systems of the country, and the weaker its ability to cope with climate change, and vice versa. Therefore, the calculation formula for the score of pressure metric is as follows:

$$
\mathrm{CF}_{\mathrm{P}}=\frac{1}{2} \sum_{\mathrm{t}=1}^{2} \mathrm{MC}_{\mathrm{t}}
$$

where:

$t$ : the number of the next leve of indicators

$C F_{P}$ : the socre of Pressure Metric

$M C_{t}$ : the socre of each first-class indicator in Pressure Metric (2) Sensitivity Metric

The metric of sensitivity is a multidimensional, quantitative response relationship between the extrinsic stress of the exposed system or unit and its consequences, and is also an extent of positive or negative effects caused by the stress of the exposed system or unit [10].

Table 1. The Comprehensive evaluation index system of PSA Model.

\begin{tabular}{|c|c|c|c|c|}
\hline Dimension & $\begin{array}{l}\text { First-class } \\
\text { indicator }\end{array}$ & Indicator Description & Second-class indicator & Feed-back \\
\hline \multirow{7}{*}{ Pressure $A_{l}$} & \multirow{4}{*}{$\begin{array}{l}\text { Climate Change } \\
B_{l}\end{array}$} & \multirow{3}{*}{ Weather change } & Average annual temperature $C_{l}$ & + \\
\hline & & & Average annual wind speed $C_{2}$ & + \\
\hline & & & Average annual precipitation $C_{3}$ & + \\
\hline & & Extreme weather disaster & The number of days of extreme climatic disasters $C_{4}$ & + \\
\hline & \multirow{3}{*}{$\begin{array}{l}\text { Urban } \\
\text { development } B_{2}\end{array}$} & Economic structure level & The proportion of tertiary industrial output-value $C_{5}$ & - \\
\hline & & The level of urbanization & Urbanization rate $C_{6}$ & + \\
\hline & & Fossil fuel consumption & Terminal energy consumption $C_{8}$ & + \\
\hline \multirow{6}{*}{ Sensitivity $A_{2}$} & \multirow{3}{*}{$\begin{array}{l}\text { Natural } \\
\text { environment } B_{3}\end{array}$} & Hydrology and water resources & Proportion of water used for ecology and environment $C_{9}$ & + \\
\hline & & Coastal and low-lying areas & Annual water consumption per capita $C_{10}$ & + \\
\hline & & Vegetation ecosystem & National afforestation coverage $C_{11}$ & - \\
\hline & \multirow[b]{3}{*}{ Social economy $B_{4}$} & \multirow{2}{*}{ Social and economic development } & Economy density $C_{12}$ & + \\
\hline & & & Year-end balance per capita $C_{13}$ & - \\
\hline & & Population development & Population density $C_{14}$ & + \\
\hline \multirow{5}{*}{$\begin{array}{l}\text { Adaptive } \\
\text { Capability } A_{3}\end{array}$} & \multirow{2}{*}{$\begin{array}{l}\text { Economic } \\
\text { capacity } B_{5}\end{array}$} & \multirow{2}{*}{$\begin{array}{l}\text { The level of economic development } \\
\text { Government financial support } \\
\text { capabilities }\end{array}$} & Real GDP per capita $C_{17}$ & - \\
\hline & & & Per capita financial income $C_{18}$ & - \\
\hline & Human and social & Education level & The number of college students per 10000 people $C_{l 9}$ & - \\
\hline & development $B_{6}$ & Social justice & Poverty index $C_{20}$ & - \\
\hline & Infrastructure & Infrastructure & Highway density $C_{21}$ & - \\
\hline
\end{tabular}




\begin{tabular}{lllll}
\hline Dimension & $\begin{array}{l}\text { First-class } \\
\text { indicator }\end{array}$ & Indicator Description & Second-class indicator & Feed-back \\
\hline and technology & & The proportion of investment in environmental protection \\
& support $B_{7}$ & Environmental governance & control in GDP $C_{22}$ & Standard-reaching rate of discharge of industrial waste water \\
& & $C_{23}$ & - \\
& & The proportion of R\&D expenditure in GDP $C_{24}$ & - \\
\hline
\end{tabular}

P.S. +:positive feedback;-:negative feedback.

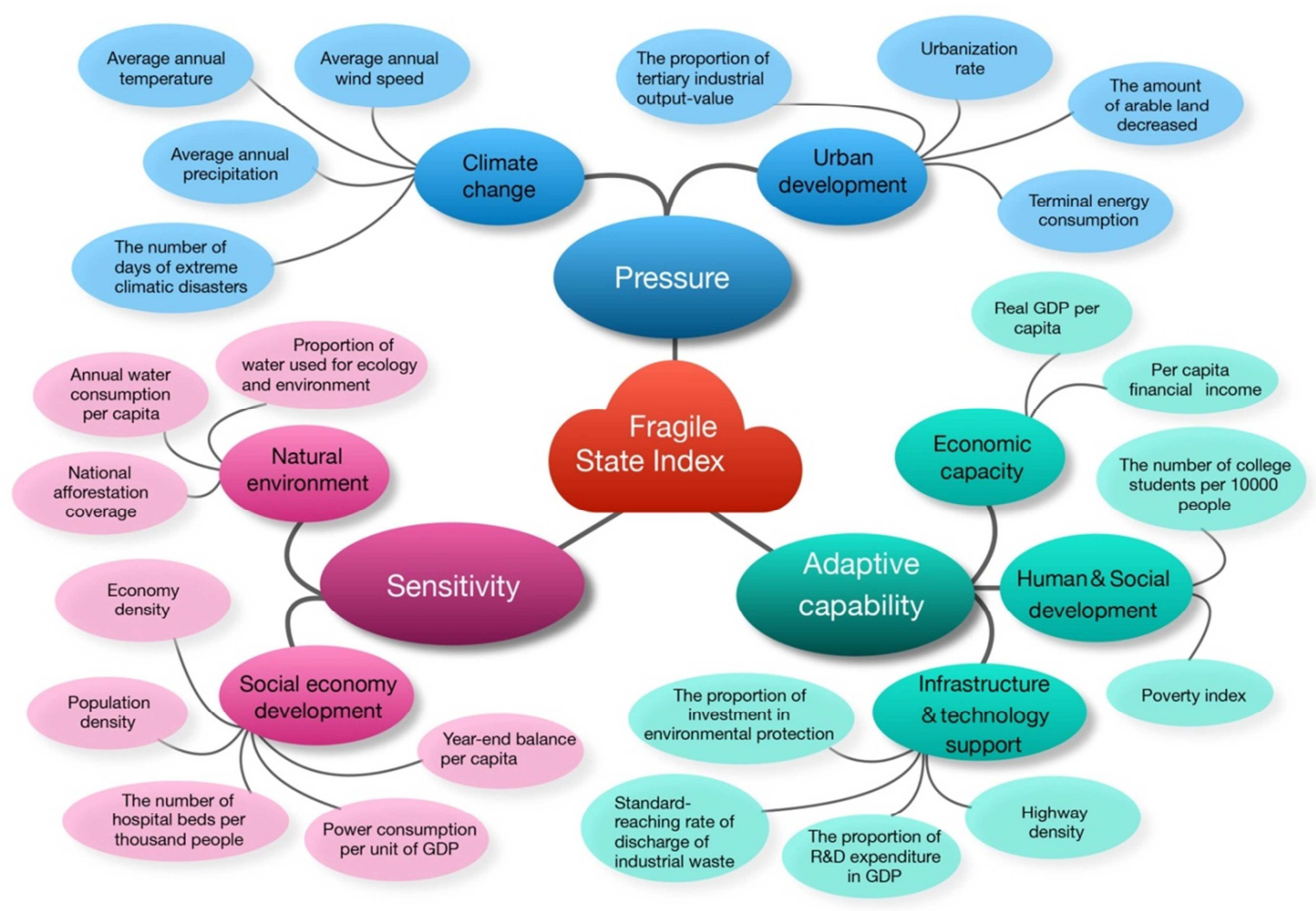

Figure 2. The national fragile state index (FSI) system diagram.

The higher the sensitivity metric, the more susceptible the system is to climate change, and vice versa. Therefore, the calculation formula for the score of sensitivity metric is as follows:

$$
C F_{S}=\frac{1}{2} \sum_{p=1}^{2} M C_{p}
$$

where:

$p$ : the number of the next leve of indicators

$C F_{S}$ : the socre of Sensitivity Metric

$M C_{P}$ : the socre of each first-class indicator in Sensitivity Metric

(3) Adaptive Capability Metric

The metric of adaptive capability is the ability of the system to adapt itself to actual or expected climate change pressures and to respond to and deal with the consequences of climate change that has already occurred. It is considered as a function of wealth, technology, education, information, availability of resources, system stability and management capabilities [11]. The higher the adaptive capability metric, the lower the ability to respond to climate change, and the higher the vulnerability of the composite system, and vice versa. Therefore, the calculation formula for the score of adaptive capability metric is as follows:

$$
C F_{A}=\frac{1}{3} \sum_{m=1}^{3} M C_{m}
$$

where:

$m$ : the number of the next leve of indicators

$C F_{A}$ : the socre of Adaptive Capability Metric

$M C_{m}$ : the socre of each first-class indicator in Adaptive Capability Metric

Therefore, the Fragile State Index can be expressed as:

$$
F S I=\frac{1}{3}\left[C F_{P}+C F_{S}+\left(1-C F_{A}\right)\right]
$$

Because of the negative correlation between adaptability and vulnerability, this essay uses " 1 " to subtract the score of adaptive capability metric $\left(C F_{A}\right)$. Finally, the FSI value is 
calculated and the value range is from " 0 " to " 1 ". " 0 " means "least vulnerable", and "1" means "weakest" [4], so this model can identify the when the state is a fragile, vulnerable, or stable.

\subsection{Application of Model}

This model is able to determine a country's fragility and simultaneously measures the impact of climate change, which can show in what ways, the state may be less fragile without these effects. Through this model, it is obvious to find which interventions could be taken for a state to mitigate the risk of climate change and prevent a country from becoming a fragile state. A country's climate change can not only directly affects the cost of the country's expenditure, but also indirectly affects the population density, population health, and food production reduction through changes in precipitation and changes in temperature. This in turn exacerbates the instability in the region.

\section{Research Results}

\subsection{The Solution of the Model}

The passage chose the Philippines as the research object. After collecting the data of various secondary indicators over the past decade and normalizing the data, a weight to each secondary index using the entropy method was assigned and finally the values were substituted into the PSA model. By comparing the vulnerability values, the years in which the climate abruptly changed is apparent, and it is easy to prove whether the Fragile State Index has changed significantly. The specific steps for solving the model are as follows:

\subsubsection{Normalize the Data}

For positive indicators, within a certain range, the larger the index, the better. The larger the index value, the greater the contribution to the Fragile State Index. The specific calculation formula is as follows:

$$
P_{i j}=\frac{x_{i j}-x_{i, \min }}{x_{i, \max }-x_{i, \min }}
$$

For negative indicators, within a certain range, the smaller the indicator, the better. The smaller the index value, the greater the contribution to the vulnerability index. The specific calculation formula is as follows:

$$
P_{i j}=\frac{x_{i, \max }-x_{i j}}{x_{i, \max }-x_{i, \text { min }}}
$$

where:

$j$ : the $j$-th sample $(j=1, \ldots, n)$

$P_{i j}$ : the $i$-th index value of the $j$-th sample after normalization

$x_{i j}$ : the original observation value of the $\boldsymbol{i}$-th index of the $\boldsymbol{j}$-th sample

\subsubsection{Calculate the Proportion of the i-th index Value of the $j$-th Sample in the Total of the Index Value}

$$
Y_{i j}=\frac{P_{i j}}{\sum_{j=1}^{n} P_{i j}}
$$

\subsubsection{Calculate the Information Entropy of the Index}

According to the definition of information entropy in information theory, the information entropy of a group of data is expressed as:

$$
E_{j}=-\ln (n)^{-1} \sum_{i=1}^{n} Y_{i j} \ln Y_{i j}
$$

$$
\text { If } Y_{i j}=0 \text {, then define that } \lim _{Y_{i j} \rightarrow 0} Y_{i j} \ln Y_{i j}=0 \text {. }
$$

\subsubsection{Determine the Weight of Each Indicator}

According to the calculation formula, the information entropy of each index is calculated as: $E_{l}, E_{2,} \ldots, E_{k}$.

According to the entropy weight method, the weight of each vulnerability index under different dimensions is calculated.

$$
\mathrm{W}_{\mathrm{i}}=\frac{1-\mathrm{E}_{\mathrm{i}}}{\mathrm{k}-\sum \mathrm{E}_{\mathrm{i}}}(i=1,2, \ldots, k)
$$

\subsubsection{Get the Second-Class Indicators Score}

$$
W I S_{i}=P_{i} \times W_{i}
$$

where:

$W_{i}$ : the weight of the $i$-th second-class index

$W I S_{i}$ : the score of each second-class indicator

\subsubsection{Get the First-Class Indicators Score}

Sum the scores of each second-class indicator, and divide the sum of the weights of the second-class indicators to get the score of each first-class indicator.

$$
M C=\frac{\sum_{i=1}^{a} W_{I} S_{i}}{\sum_{i=1}^{a} W_{i}}
$$

where:

$a$ : the number of second-class indicators in each first-class indicator

$M C$ : the score of each first-class indicator

\subsubsection{Calculate the FSI}

Using the formula (4), the Fragile State Index (FSI)of the Philippines from 2004 to 2015 was obtained.

\subsection{Analysis of the Results of the Model}

The Philippines' FSI has been volatile since the period of 2003-2013. The FSI from 2005 to 2008 has declined year by 
year. However, it has gradually increased since 2008 and FSI of Philippine suddenly increased in 2012.

Table 2. The weight of the second-class indicators in Philippines.

\begin{tabular}{lll}
\hline Second-class indicator & weight & Second-class indicator \\
\hline Average annual temperature $C_{1}$ & 0.054 & Economy density $C_{12}$ \\
Average annual wind speed $C_{2}$ & 0.049 & Population density $C_{14}$ \\
Average annual precipitation $C_{3}$ & 0.065 & The number of hospital beds per thousand people $C_{15}$ \\
The number of days of extreme climatic disasters $C_{4}$ & 0.048 & Power consumption per unit of GDP $C_{16}$ \\
The proportion of tertiary industrial output-value $C_{5}$ & 0.052 & Real GDP per capita $C_{17}$ \\
Urbanization rate $C_{6}$ & 0.049 & Per capita financial income $C_{18}$ \\
The amount of arable land decreased $C_{7}$ & 0.047 & 0.142 \\
Terminal energy consumption $C_{8}$ & 0.050 & The number of college students per 10000 people $C_{19}$ \\
Annual water consumption per capita $C_{10}$ & 0.052 & The proportion of R\&D expenditure in GDP C \\
\hline
\end{tabular}

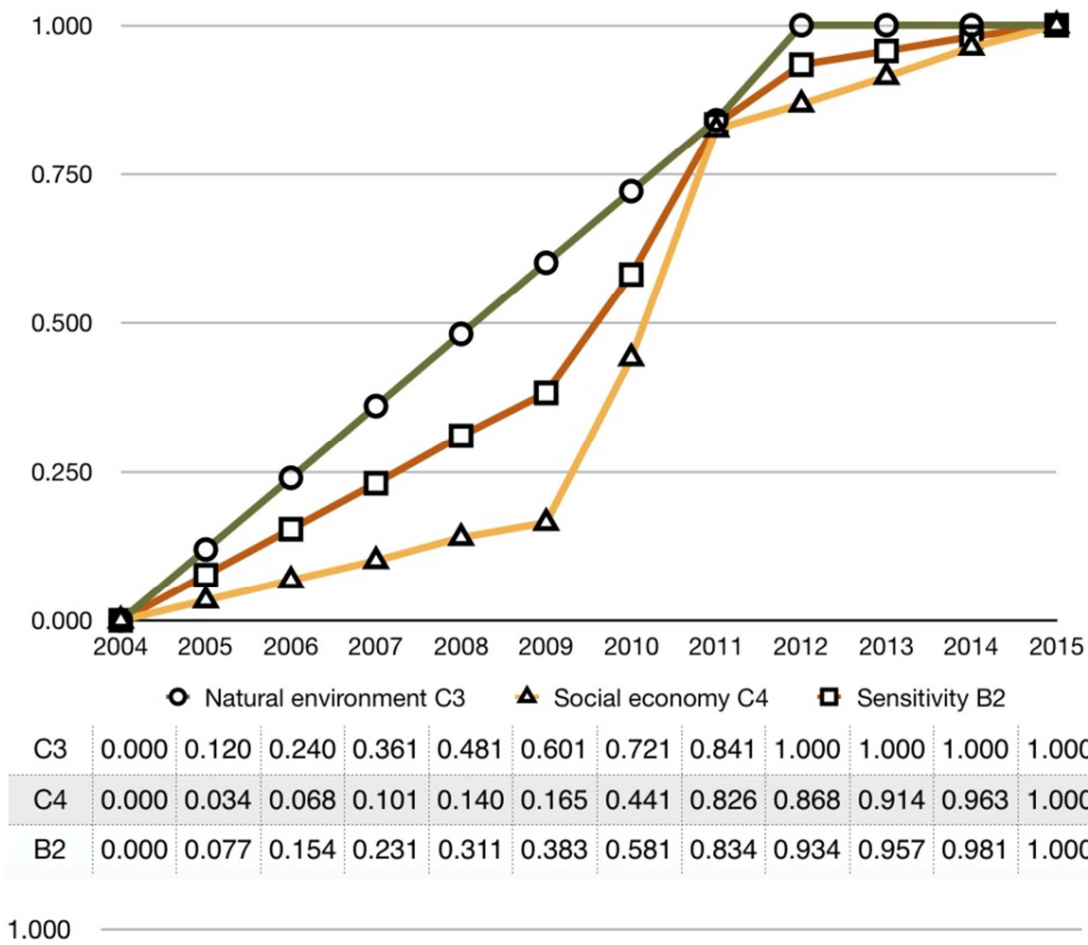

0.750
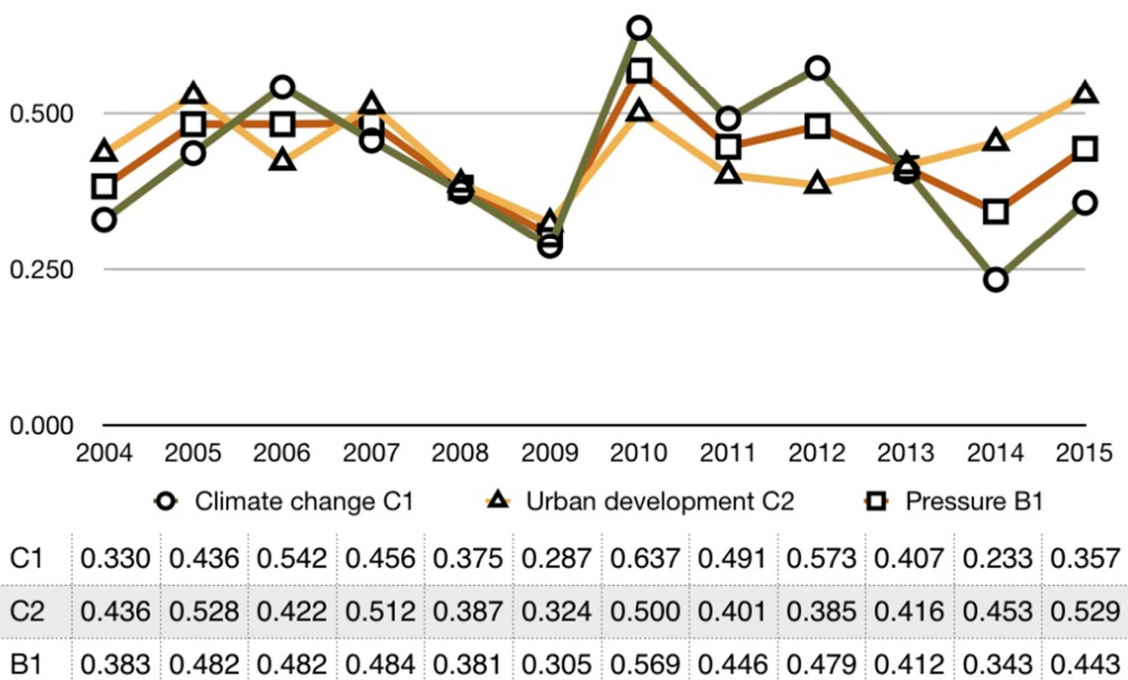


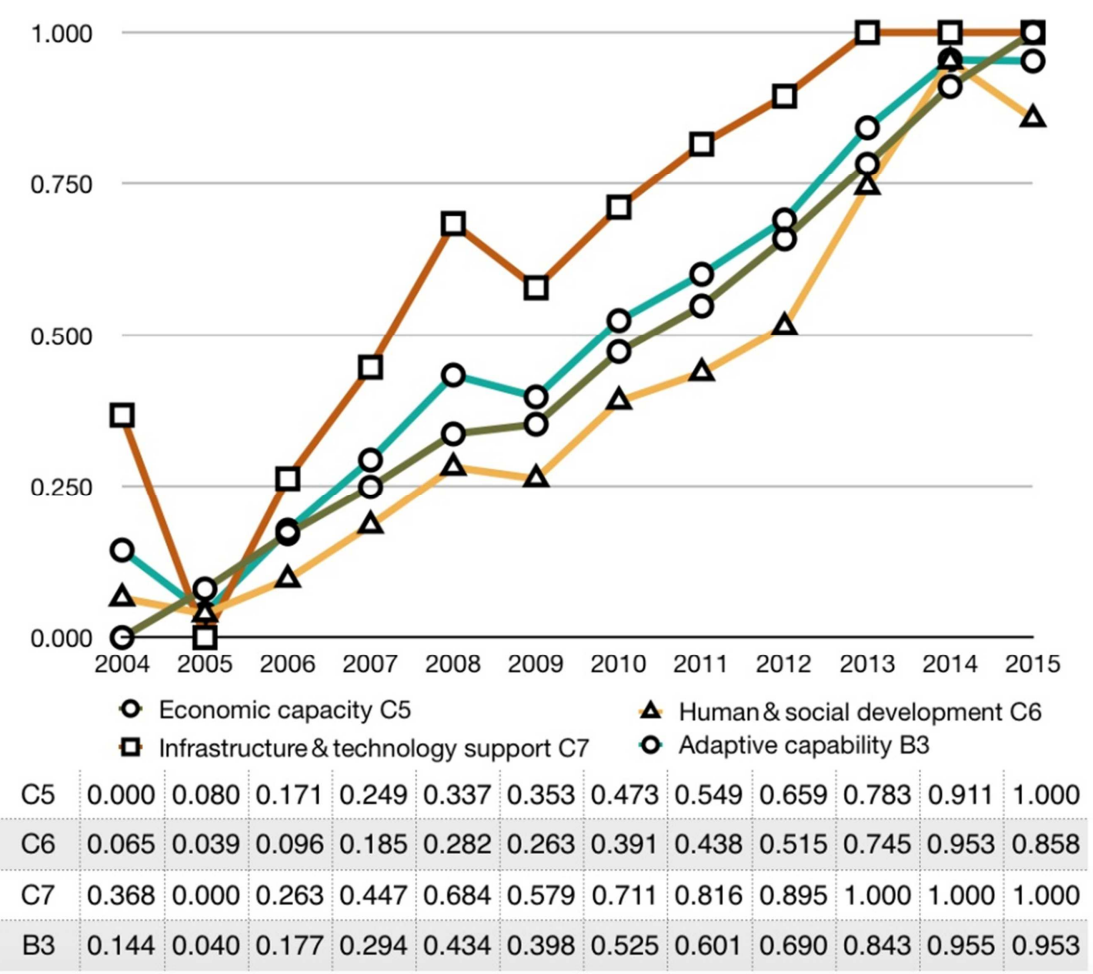

Figure 3. The score of each first-class indicators in Philippines (2004-2015).

1.000

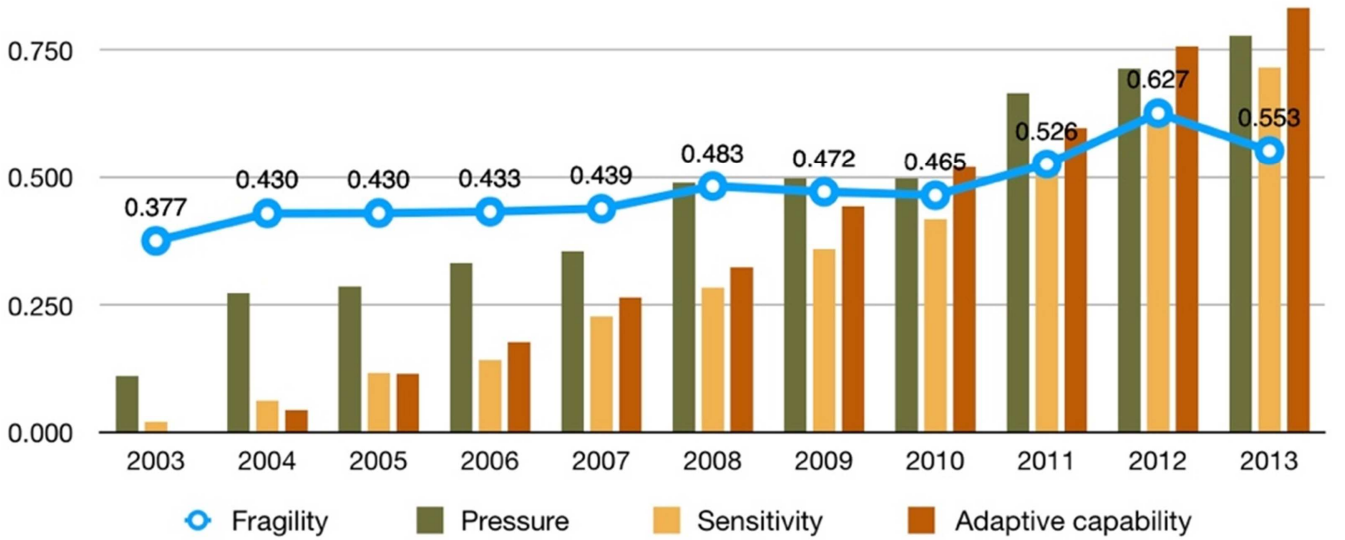

Figure 4. The changes of FSI in Afghan (2003-2013).

It was mainly due to the impact of extreme weather disasters. By collecting data, it is clear that the rainfall in 2012 reached the maximum value over the years, making the highest FSI in the year, reaching 0.574. It indicated that extreme weather disasters, especially floods, had a greater impact on the Philippines, causing huge losses of life and property, and even influencing the economic development of the Philippines and people's normal production and life. This would greatly increase the fragility of the natural economic and social complex system in the Philippines. At that time, The Philippines had a great disadvantage in dealing with climate disasters such as floods and typhoons. What' more, climate disasters were changing the distribution of the population in the Philippines. The index fell slightly from 2005 to 2007, but the rate was modest, which was mainly due to the fact that the pressure metric within the Philippines' Fragile State Index for the past three years remained unchanged and the adaptive capability metric was greatly increased.

\subsection{Determination of a Tipping Point}

To further study the relationship between national vulnerability and climate change, this article defines a critical point to define and predict whether a country is fragile or non-fragile. This passage clustered the twelve FSI values obtained from the Philippines by SPSS and divided the data into two categories by the K-means clustering algorithm:the first category of FSI value range is from 0.41 to 0.49 , and the second category of that is from 0.51 to 0.57 . It conducted 
ANOVA analysis on the indicators of the two groups. We found that the differences of the indicators between the two categories were significant ( $\boldsymbol{p}$ values were all less than $1 \%$ of the significance level). This showed that it was reasonable to divide the 12 FSI values into two categories.

The paper used the same research method to obtain Afghanistan's FSI, and then conducted a cluster analysis of 11-year FSI in Afghan. Similarly, it also got the critical value $(0.5)$, which proved that the result was reasonable.

\section{Advice on National Interventions}

In order to prevent a country from becoming a fragility country, some interventions are needed to mitigate the risk of climate change. To improve the country's sustainable development, based on the above chart, there are many ways to reduce the development pressure, diminish the sensitivity of development and enhance the adaptive capability. The specific measures are as follows:
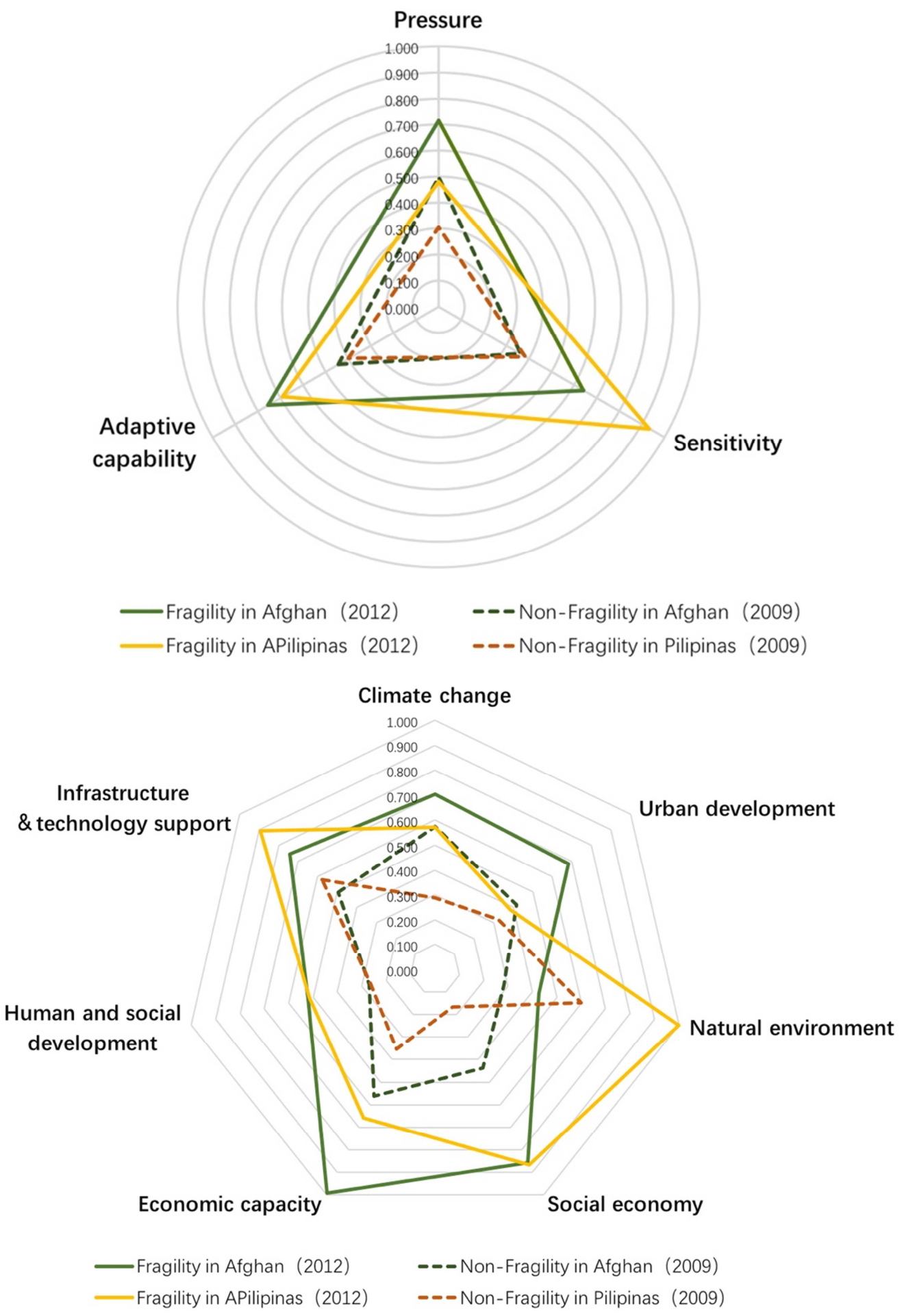

Figure 5. Comparison of different parameters between Fragile and Non-Fragile situations. 


\subsection{Reduce Development Pressure}

The government can strengthen its ability to respond to extreme weather disasters by enhancing urbanization, persist in implementing regional coordinated development and new-type urbanization strategies, and increase the proportion of the tertiary industry's output value in GDP. The Philippines regards minerals as a pillar industry of the country. And the highly "path-dependent" nature of the country's economic development on resources and the resulting low efficiency are the key factors constraining its sustainable development. So we can start from two aspects: "resources" and "benefit":reduce the disturbance of resource depletion on economic development and gradually reduce the status and role of resource industry in the regional economy. Additionally, vigorously develop small and medium-sized enterprises and private enterprises to increase the vitality of regional economic development, thereby increasing social employment and per capita income [12].

\subsection{Reduce Development Sensitivity}

The government can increase the intensity of afforestation and expand the country's green area to effectively mitigate the impact of climate change. And it should also expand the scale of hospitals so that people will not be displaced and have no cure at the time of disasters. The government is supposed to transform the resource industry from single to comprehensive, increase scientific research investment, use traditional high-tech technology to arm traditional resource industries, develop them into precision processing and deep processing, and advance into high-tech fields in accordance with their own conditions. At the same time, it's necessary to increase investment in education and research, strengthen the building of teams in the field of environmental and health management, and attach importance to personnel training.

\subsection{Increase Adaptive Capability}

The government are expected to strengthen the governance of environmental pollution. For instance, increasing investment in environmental protection to ulteriorly achieve coordinated development of population, economy and the environment. More importantly, it is also a good way to strengthen residents' economic capacity and increase per capita fiscal revenue and per capita GDP. As the embodiment of the will of the people, government is also supposed to apply supporting technologies to adapt to climate change and reduce the use of energy and greenhouse gas emissions. Beyond that, emphasizing the importance of planning for adapting to climate change and incorporating it into the existing planning system to form a sound adaptive planning framework should be a priority which is made by government. Encourage the implementation of urban planning action plans, research and practices that adapt to climate change, which means that everyone should turn passive into initiative and identify the effects and hazards of climate change in advance. By doing so, one can enhance the adaptability and resilience of the country to cope with climate change [13].

\section{Conclusion}

This paper has an important reference to studying the impact of climate change on the stability of the country. It will help improve the recognition of "fragility countries" and improve the government's capacity for preventing and mitigating climate disasters as well as improving emergency management level. In the future, the government should include climate risk management as an important part of urban and rural planning. According to the different vulnerability characteristics of each city, the government will formulate emergency response plans for different focuses. It is necessary to place great emphasis on the importance of strategic and forward-looking policies, integrate various resources within and outside the country, and actively adapt to the challenges posed by climate change to regional instability.

The drawback is that some index datas are missed. To some extent, the missing data can still bring the errors in evaluation. Therefore, in the next step, examples from more countries will be used to verify the accuracy and objectivity of the research method, and the improved model is expected to be suitable for studying the effects of climate change on the instability of cities and regions.

\section{References}

[1] Füesel H M. Vulnerability:ageneraly applicable conceptual framework for climate change research[J]. Global Environmental Change, 2007, 17 (2):155-167.

[2] Moss R H, Brenkert A L, Malone E L. Vulnerability to climate change: A quantitative approach $[\mathrm{J}]$. Advances in Science and Research, 2001 (1): 1-88.

[3] Klein R J T, Nichols R J. Asesment of coastal vulnerability to climate change [J]. Ambio, 1999, 28 (2):182-187.

[4] Tan Shuhao, Tan Wenlie, Li Qingting, Li Tingyu, Zhu Yong, Zhang Qiaoyun, Liu Bo. Analysis of herdsmen's social vulnerability under the pressure of climate change - Based on the investigation of 4 animal husbandry flags in Xilinguole League of Inner Mongolia[J]. Chinese Countryside Economy. 2016 (07).

[5] Xu Tingting, $\mathrm{Xu}$ Changle, Liu Yang. Research on the Evaluation of Social and Economic Vulnerability of Shanghai under the Background of Global Climate Change_-Based on PSR Model[J]. Resource Development and Market. 2015 (03).

[6] Feng Chunyan. Study on Social Vulnerability of Drought Disaster in Shandong Province[D]. Qufu Normal University. 2017.

[7] Qiao Mengmeng. Study on Water Resources Vulnerability in Suzhou City[D]. Suzhou University of Science and Technology. 2017.

[8] Niemeijer, D. Developing Indicators for Environmental Policy: Data-driven and Theory-driven Approaches Examined by Example[J]. Environmental Science \& Policy, 5 (2): 91-103, 2002. 
[9] IPCC. Climate Change 2007-The Physical Science Basis: Working Group I Contribution to the Fourth Assessment Report of the IPCC [M]. Cambridge University Press, 2007.

[10] Chen Ping, Chen Xiaoling. A Review of the Research on the Vulnerability of Human-environment Coupling System under Global Environmental Change [J]. Progress in Geography. $2010(04)$

[11] Mccarthy, J. J.; Canziani, O. F.; Leary, N. A.; Dokken, D. J. and White, K. S. (eds.). Climate Change 2001: Impacts, Adaptation, and Vulnerability: Contribution of Working Group
II to the Third Assessment Report of the Intergovernmental Panel on Climate Chang [M]. Cambridge University Press, 2001.

[12] Sun Pingjun, Xiu Chunliang. Study on the vulnerability of mining cities' economic development based on PSE model [J]. Geographical Research. 2011 (02).

[13] Wang Yue, Tian Shen, Zhao Qiping, Li Xudong. Research Progress on Adaptability of High-Temperature Heat Wave Weather Based on Vulnerability [J]. Journal of Environment and Health. 2017 (03). 